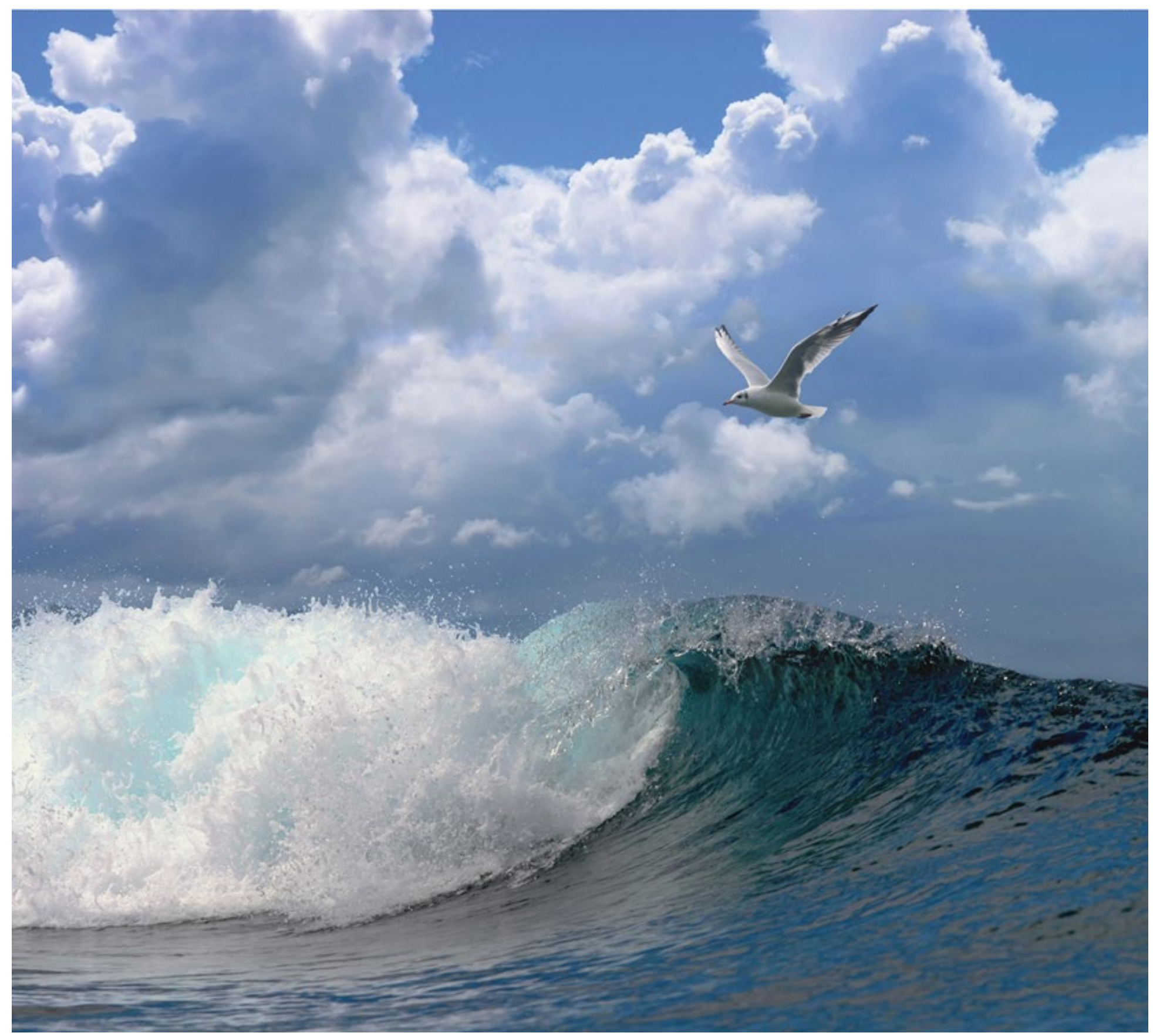

\title{
Fishing activity near Petrogas offshore pipelines, 2020
}




\section{Fishing activity near Petrogas offshore pipelines, 2020}

Author(s): Niels Hintzen

Wageningen Marine Research

Wageningen Marine Research

Haarlem, June 2021

CONFIDENTIAL no

Wageningen Marine Research report C055/21 
Keywords: Offshore Pipeline; Trawling Fishery Factor; Risk- \& Probability Analysis.

Client: $\quad$ Petrogas E\&P Netherlands B.V.

Attn.: H. Kuijpers

Laan van Zuid Hoorn 14

2289 DE Rijswijk

This report can be downloaded for free from https://doi.org/10.18174/549049

Wageningen Marine Research provides no printed copies of reports

Wageningen Marine Research is ISO 9001:2015 certified.

\section{(C) Wageningen Marine Research}

Wageningen Marine Research, an institute within the legal entity Stichting Wageningen Research (a foundation under Dutch private law) represented by Dr.ir. J.T. Dijkman, Managing director

KvK nr. 09098104, WMR BTW nr. NL 8113.83.696.B16.

Code BIC/SWIFT address: RABONL2U IBAN code: NL 73 RABO 0373599285
Wageningen Marine Research accepts no liability for consequential damage, nor for damage resulting from applications of the results of work or other data obtained from Wageningen Marine Research. Client indemnifies Wageningen Marine Research from claims of third parties in connection with this application.

All rights reserved. No part of this publication may be reproduced and / or published, photocopied or used in any other way without the written permission of the publisher or author.

A_4_3_2 V31 (2021) 


\section{Contents}

Fishing activity near Petrogas offshore pipelines, 2020

Summary

1 Introduction

$2 \quad$ Assignment

$3 \quad$ Materials and Methods $\quad 7$

4 Results $r 11$

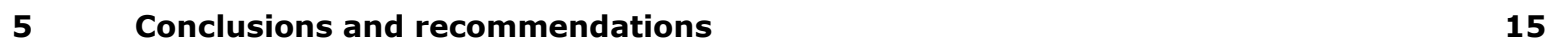

$6 \quad$ Quality Assurance $r$

$\begin{array}{lr}\text { References } & 17\end{array}$

$\begin{array}{lr}\text { Justification } & 18\end{array}$ 


\section{Summary}

On the North Sea bottom lie numerous pipelines to link oil- or gas offshore drilling units, - platforms and processing stations on land. Although pipeline tubes are coated and covered with protective layers, the pipelines risk being damaged through man-made hazards like anchor dropping and fishing activities with bottom trawls.

Petrogas E\&P Netherlands B.V. works towards integrated risk assessment of pipelines. Spatial maps of fishing activity would contribute to this risk assessment. Therefore, WMR was tasked to quantify the amount of fishing activity in the vicinity of Petrogas E\&P Netherlands B.V. pipelines. Fishing activity has been quantified at a spatial scale of approximate $3800 \mathrm{~m} 2$ blocks (68m by $56 \mathrm{~m}$ ) using fishing Vessel Monitoring System (VMS) data from the year 2020.

The results in this study show that larger vessels as well as smaller vessels do operate a fishing in the vicinity of the pipelines located closer to shore. In the northern part of the EEZ, fishing intensity of larger vessels is low and negligible for smaller vessels and shrimp trawlers. The highest fishing intensity (number of times a full grid cell is trawled) is recorded close to the IJmuiden harbour due to shrimp trawling activity and amounts to an estimated 3-4 times trawling intensity around the pipelines. It is however realised with gears substantially lighter than traditional beam trawls. This fishing intensity is below the range of 5-10 times a year estimated in the most intensively fished areas of the North Sea.

The indicators calculated in this study, reflecting number of potential interactions (fishing effort) of trawling vessels with the pipelines and the potential severity of these interactions (fishing intensity), may contribute to the risk assessment. It should be noted, however, that owing to seasonal changes in fish distribution and yearly changes in fishing gear characteristics, these maps do not provide an accurate base for the prediction of future fishing impact. 


\section{Introduction}

On the North Sea bottom lie numerous pipelines to link oil- or gas offshore drilling units, - platforms and processing stations on land. Although pipeline tubes are coated and covered with protective layers, the pipelines risk being damaged through man-made hazards like anchor dropping and fishing activities with bottom trawls. Although positions of most pipelines are known (position of older pipelines may be less accurate) an avoidance strategy of the fishing fleet is lacking. Over the past decades, around thirty hits by fishing gear were recorded that resulted in pipeline leaks in the North Sea. Each leak caused by a hit by fishing gear may be associated with substantial environmental and economic risks. Identifying these risks is therefore important in the overall risk assessment of offshore oil- and gas production activities.

Identifying where and which fishing operations are most dominant around pipeline tracks at the sea bottom can support additional and better targeted surveying operations, to check the integrity of pipelines. Survey results may, in combination with risks of fishing impact, result in tailored approaches to further protect pipelines from impacts or improve the design and position of new pipelines.

This study provides maps and shape files of fishing intensities of 2020 in a buffer area around the pipelines that can be used in a GIS application by Petrogas E\&P Netherlands B.V. to assess risks and advise on, for instance, additional survey activities. 


\section{Assignment}

Within this study, we quantify the amount of fishing effort that is allocated at, or close to, a selection of pipelines by Dutch bottom fishing vessels. In the quantification, measures of uncertainty in the data collected that represents fishing activity, are directly implemented. The final product is a shape file for the full year of 2020, containing the pipeline trajectories including a buffer area $(200 \mathrm{~m})$, and the associated fishing effort and -intensity within these areas at a aggregation level of $3800 \mathrm{~m}^{2}(68 \mathrm{~m} *$ $56 \mathrm{~m})$ grid cells. 


\section{$3 \quad$ Materials and Methods}

Since the 1st of January 2005 all fishing vessels larger than 15 meters are equipped with VMS and since the 1st of January 2012 the on-board VMS-obligation concerns all vessels larger than 12 meters. A VMS transponder sends at regular intervals a signal to a satellite providing information on the vessel's ID, position, time \& date, direction and speed. Hence, VMS is a useful data source to study the distribution of the fishing fleet both in time and space. The Dutch ministry of LNV is tasked with the collection of VMS data of all Dutch fishing vessels. VMS data of foreign vessels, even inside the EEZ, are made irregularly available for scientific purposes. All VMS positions are collected in the WGS84 reference coordinate system.

As VMS signals lack any information on the activities of the fisheries itself, e.g. regarding fishing gear, catch composition, departure harbour or vessel dimensions, for many fisheries related studies, VMS is coupled to fisheries logbooks. These logbooks report per fishing trip (approx. 2 - 5 days) when fishermen leave harbour, what gear has been used to fish, their catch composition and a rough estimate of the course grid cell location of the catches for each 24 hour period. Both VMS and logbook data report on the fishing vessel ID, which allows for the coupling of the two datasets and study fisheries distribution at finer spatial and temporal scales.

A summary of the VMS- data-processing starting with pre-process, analyse VMS- and logbook data, combine these datasets and link gear specific effort to the pipelines is given below. A more detailed description on the processing and assumptions made during this process can be found in Hintzen et al. (2013); http://edepot.wur.nl/248628.

Data pre-processing:

- $\quad$ VMS and logbook data are received from the Ministry of LNV and stored in a local database at WMR.

- VMS records are considered invalid and therefore removed from the analyses when they:

- are duplicates or pseudo-duplicates (indication of malfunctioning of VMS device or their recording)

- identify an invalid geographical position

- are located in a harbour

- are located on land

- are associated with vessel speeds $>20$ knots

- logbook records are removed from the analyses when they:

- are duplicates

- have arrival date-times before departure date-times

- overlap in time with another trip of the same vessel

Link VMS and logbook data:

- VMS and logbook datasets are linked using the unique vessel identifier and date-time stamp in both datasets available. In other words, records in the VMS dataset that fall within the departure-arrival timeframe of a trip described in the logbook are assigned the unique trip number from the logbook record which allows matching both datasets

- $\quad$ Fishing trips, using bottom gear types like beam trawlers (referred to with code TBB), otter trawlers (OTB), dredges (DRB and HMD) \& Scottish seines (SSC), showing VMS signals around the pipelines track [between latitudes 52 and 56;longitudes 3 and 5] are selected (gears such as gillnets or midwater trawls are not taken into account given their limited to non-existing contact with the seabed when in operation).

- Only VMS and logbook data of the year 2020 are used. 
Define fishing activity:

- Speed recordings obtained from VMS data are used to create frequency plots of these speeds, where along the horizontal axis the speed in knots is given and the vertical axis denotes the number of times that speed was recorded. In general, 3 peaks can be distinguished in such a frequency plot. A peak near 0 knots, associated with being in harbour/floating, a peak around the average fishing speed and a peak around the average steaming speed. These analyses are performed separately per gear type for two kW classes ( $<=225 \mathrm{~kW}$ and $>225 \mathrm{~kW}$ ) as these vessel types show different fishing behaviour and are allowed to fish in different regions.

- According to the method described above, a number of VMS records can be associated with fishing activity, depending on the gear used by the vessel. In general, vessel speeds between 1.5 and 8 knots are characterized as fishing. For small beam trawlers the selected range was approximately 2-7 knots. For large trawlers the range was approximately 4-8 knots.

Increase spatio-temporal resolution:

- VMS recordings are available for fishing vessels approximately every half - 2 hours. When the vessel speed is 4 knots, the trawling distance between two successive VMS locations, at $1 / 2$ hour pings intervals, is approximately $4 \mathrm{~km}$. Although on a yearly basis this amounts to a vast amount of spatial data, for studies such as the current one, additional detail is required to appropriately link a pipeline route to crossing fishing vessels activities. For this purpose, an interpolation routine is used which estimates intermediate locations between two successive VMS pings, also using information on headings and speeds. The routine used in this study is described in detail in Hintzen et al., 2010. On average, an additional 700 points are added in between two successive VMS pings which are by default two hours apart, resulting in a dataset with pings intervals of 10 seconds.

Define area of interest:

- In total $230 \mathrm{~km}$ pipeline trajectories were identified that needed investigation in this study. They are located in the North Sea coast off IJmuiden and in the northern part of the Dutch EEZ. (see Figure 1). The study area has further been divided into small squares (a grid) of 68x56 $\mathrm{m}$ blocks to allow for more detailed spatial analyses. 


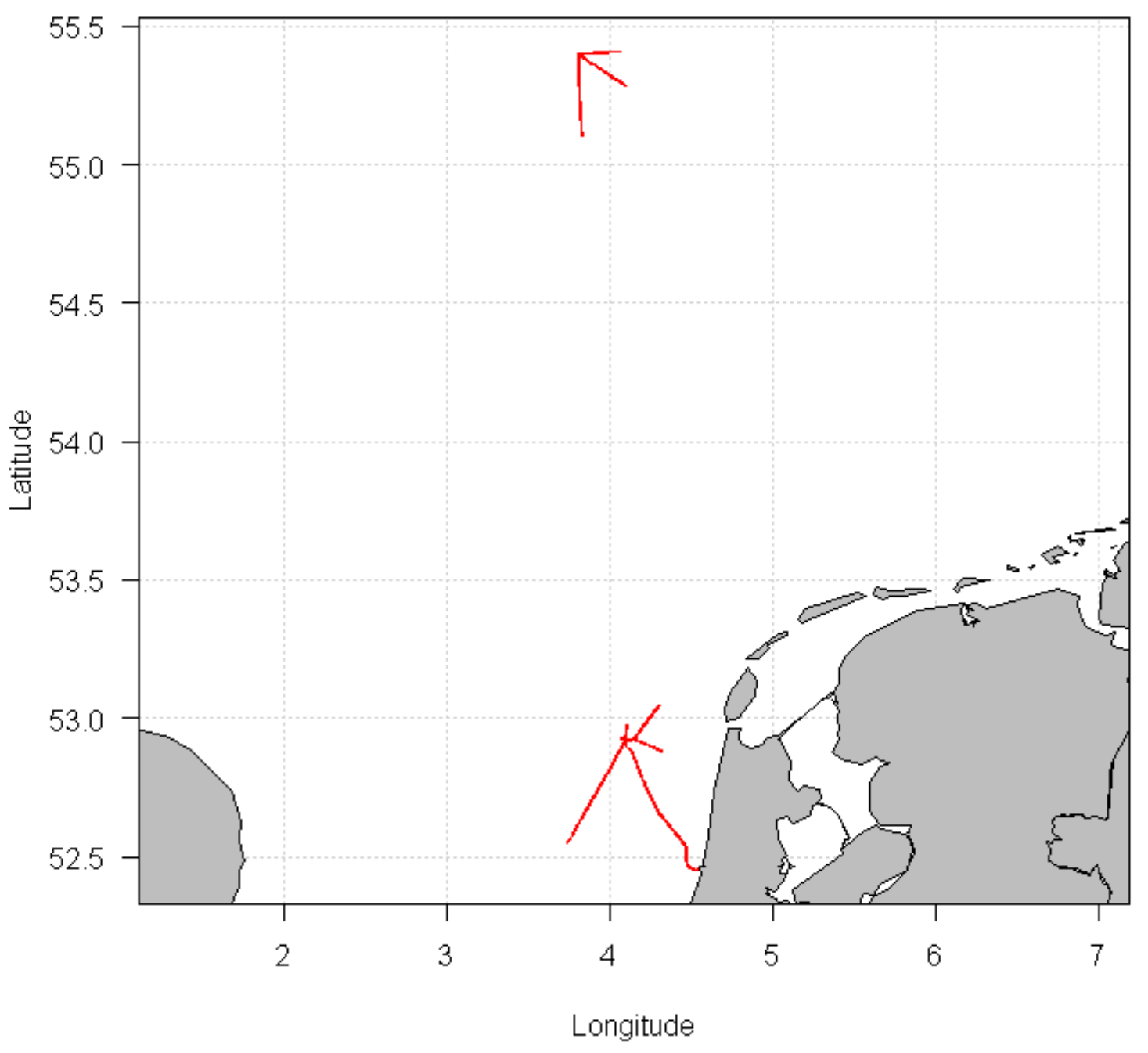

Figure 1. Dutch North Sea coast and locations of pipelines (in red) including a buffer area around the pipelines of $200 \mathrm{~m}$ (100m either side). The rectangular dashed grid identifies the ICES quadrants. Link pipeline location to fishing effort:

- We assume that a pipeline hazard may be caused by a build-up of smaller damage events caused by passages of active fishing vessels using bottom gears. The exact route of fishing vessels is however uncertain given that only every 2 hours exact vessel position data is collected and stored. Therefore, the increased spatio-temporal resolution improvements have to be made. This however, does not account for uncertainty in this interpolation method. Additionally we assume that activity is certain at the locations from which a VMS ping was send to the satellite, but certainty decreases in between these time stamps and decreases further away from the interpolated track. This together creates a 2-dimensional confidence interval for each fishing vessel movement, which can be scaled to represent the interval hours of fishing in total. Figure 2 gives a graphical representation of the interpolation and confidence interval calculation.

Note that each grid cell then represents a certain amount (measured in minutes) of fishing activity. This uncertainty is calculated assuming a grid of $68 \times 56 \mathrm{~m}$ blocks. By cumulating the fishing effort of all vessels of the fleet under consideration, the grid cell values reveal detailed spatial information of fishing activities during a year. By multiplying the fishing activity by gear with the fishing speed and gear width, and dividing by surface area of each grid cell, we calculate the fishing intensity. Finally, the pipeline location is overlaid onto the fishing activity grid to link the fishing effort to each pipeline location. A shape file is created containing the fishing activity by grid cell bounded by the pipeline trajectories. 

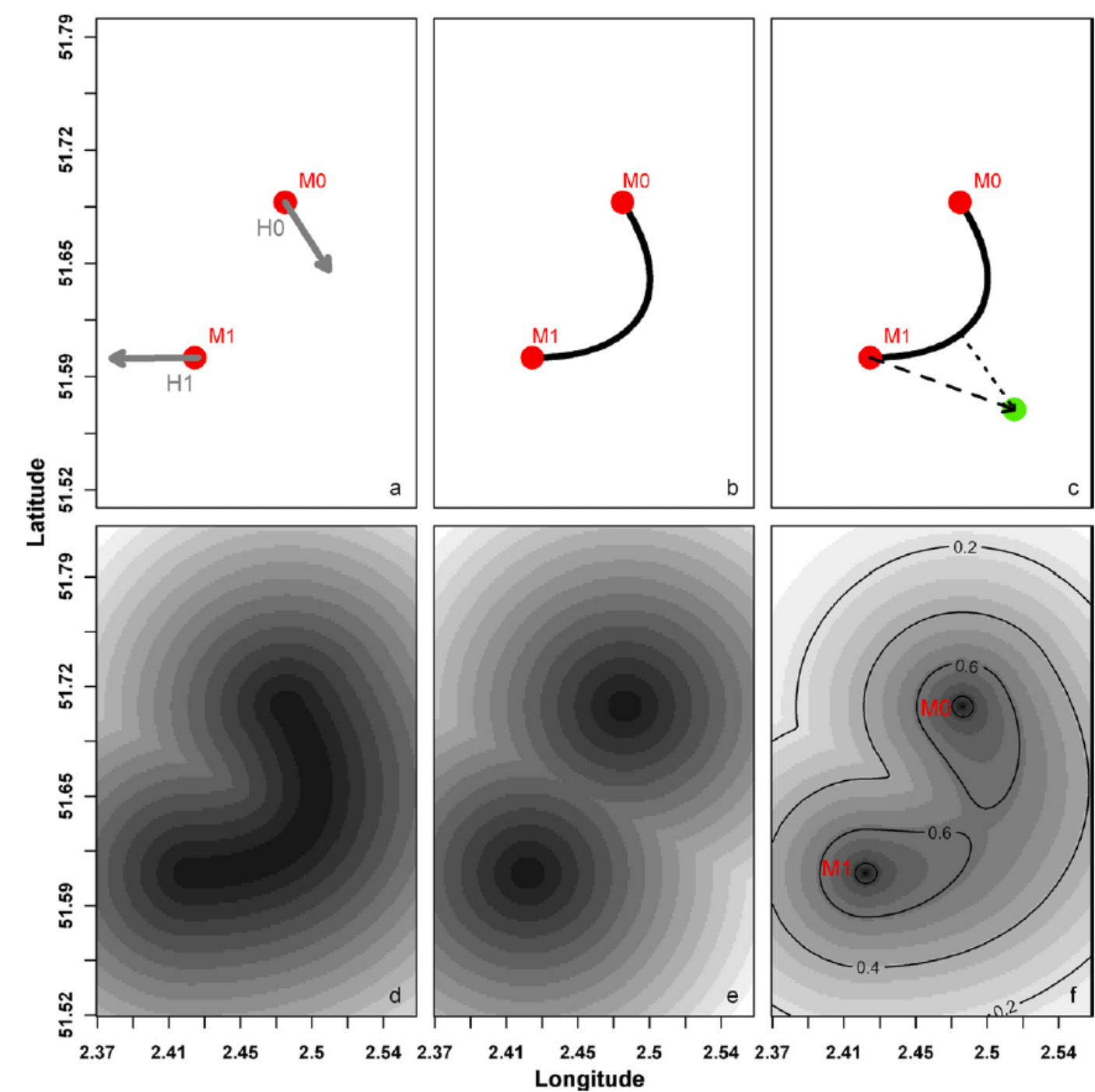

Figure 2. Schematic representation of the interpolation process starting with two succeeding VMS position registrations towards an estimated track surrounded by a confidence interval. (a) The start and end point of the vessel are represented by $M_{0}$ and $M_{1}$ respectively, the heading of the vessel at start- and end-point are represented by the small arrows $H_{0}$ and $H_{1}$. Based on the value of a scaling parameter these arrows become longer/shorter influencing the curvature of the interpolation (see panel b). For small values of this parameter, the interpolation will approximate a straight line between $M_{0}$ and $M_{1}$. (b) Interpolated track based on cubic Hermite spline (black solid line). (c) The parameter DSD for a random point on a grid (green dot) depends on the distance marked by the dashed arrow (black dashed arrow) from M1 to the green dot. (d) Shortest distance from each point on a grid to the interpolated track. Lighter grey represents more distant grid cells. (e) Shortest distance from each point on a grid to either MO or M1. Lighter grey represents more distant grid cells. (f) Interpolation between two succeeding VMS data points surrounded by a confidence interval. At positions MO and M1, values equal one.

\section{Calculation of fishing intensity}

The confidence intervals are thereafter converted into swept-area estimates based on average speed and gear width of the gears considered (beam trawl including pulse and shrimp trawl, otter trawls, dredge and flyshoot). Vessels with engines larger than 300hp were grouped into the category of large vessels and vessels with engines lower than $300 \mathrm{hp}$, excluding shrimp trawls, were grouped into the category of small vessels. Due to the low weight of the gear of the shrimp trawls, these were considered separately. The swept-area estimates for each of these three gear groups was converted into swept-area-ratio estimates by dividing the swept-area estimate per grid cell by the surface area of the grid cell. This indicator, often referred to as fishing intensity, is a proxy for the number of times a pipeline has been crossed, although not explicitly the same. 


\section{$4 \quad$ Results}

The results are shown for the three gear groups: large vessels, small vessels and shrimp trawls. The maps below show on the left-hand panels including the fishing intensity estimate including a subset $(\sim 10 \%)$ of the actual VMS pings the analyses is based on. On the right-hand side, the same map is given but without the VMS pings. For each gear category the pipelines close to the Dutch coastline and in the northern part of the EEZ are presented separately. Shapefiles of each pipeline segment is made available to the client.
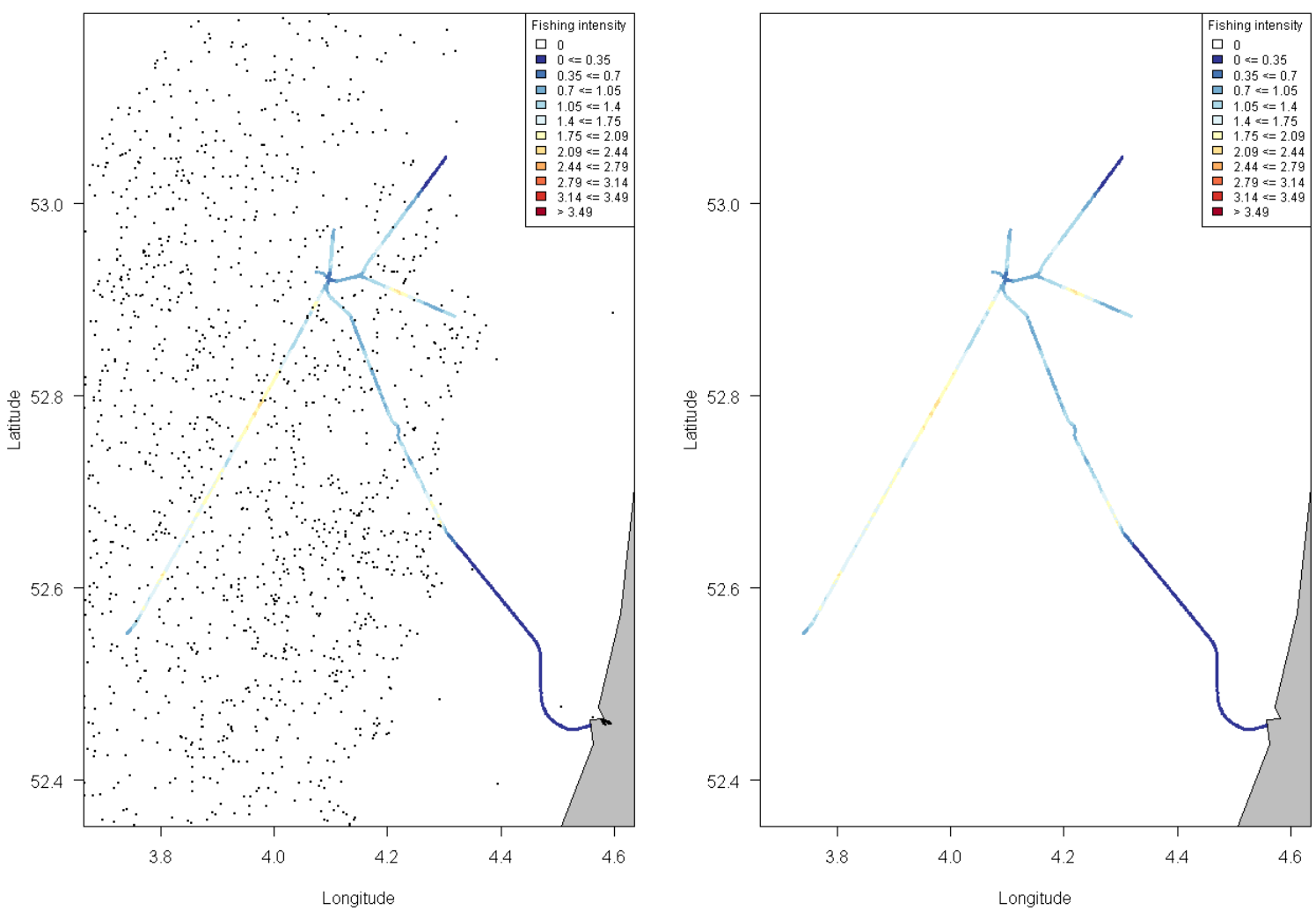

Figure 3. Fishing intensity of large bottom trawl vessels near the Dutch coastline. Left-hand figure includes $\sim 10 \%$ of the VMS pings (black dots) that the analyses has been based on. 

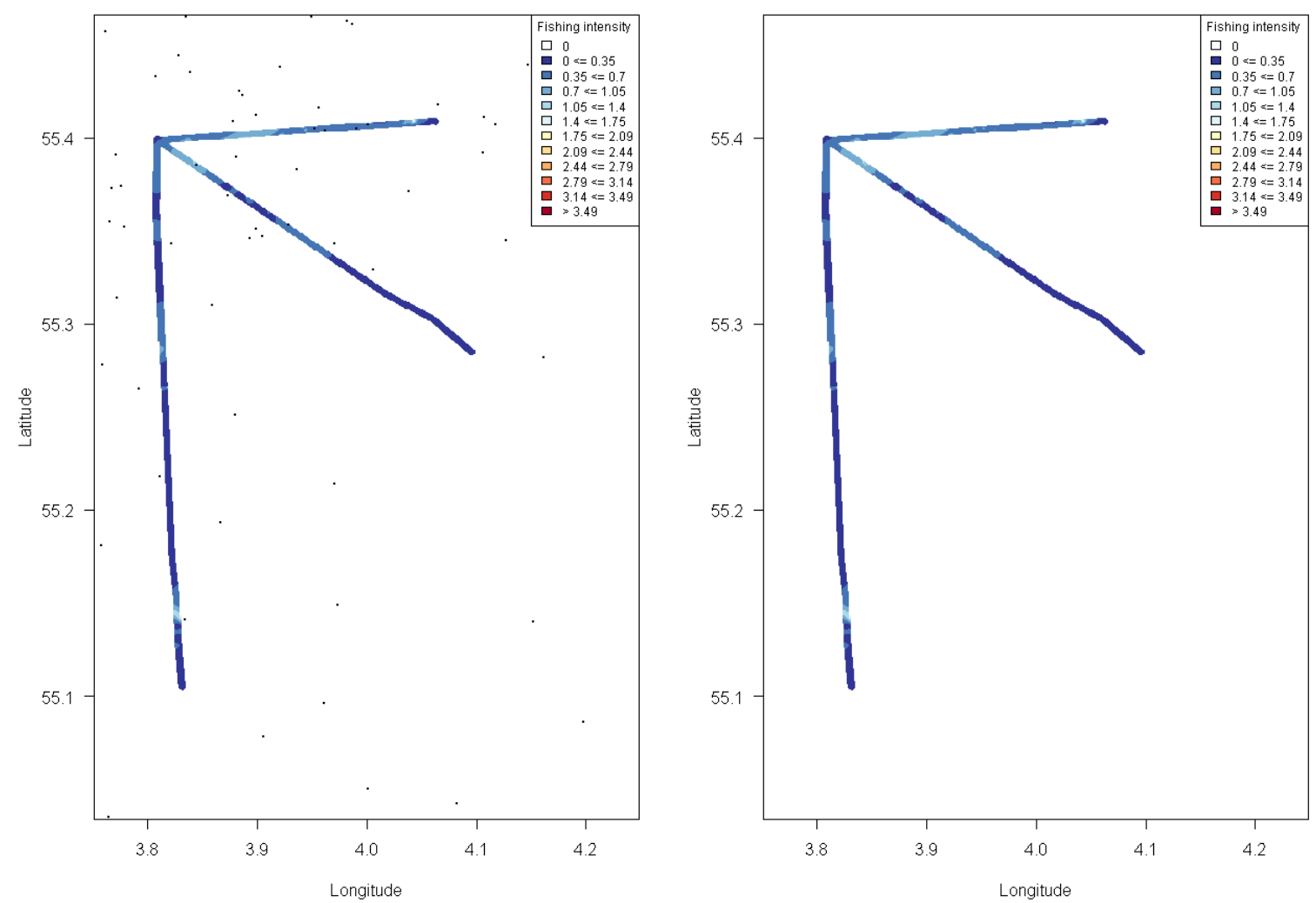

Figure 4. Fishing intensity of large bottom trawl vessels in the northern part of the Dutch EEZ. Lefthand figure includes $\sim 10 \%$ of the VMS pings (black dots) that the analyses has been based on.
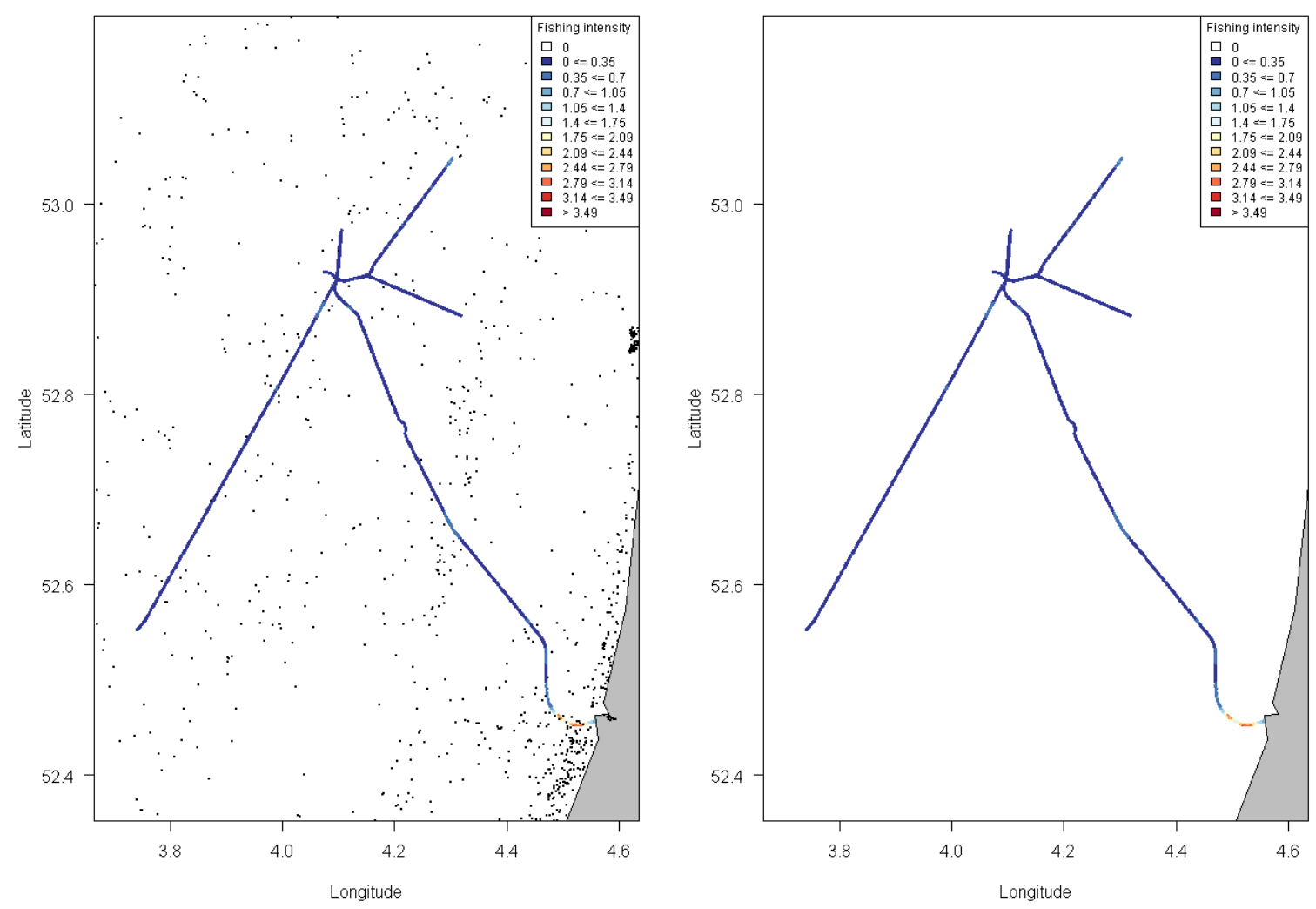

Figure 5. Fishing intensity of small bottom trawl vessels (excl shrimp trawlers) near the Dutch coastline. Left-hand figure includes $\sim 10 \%$ of the VMS pings (black dots) that the analyses has been based on. 

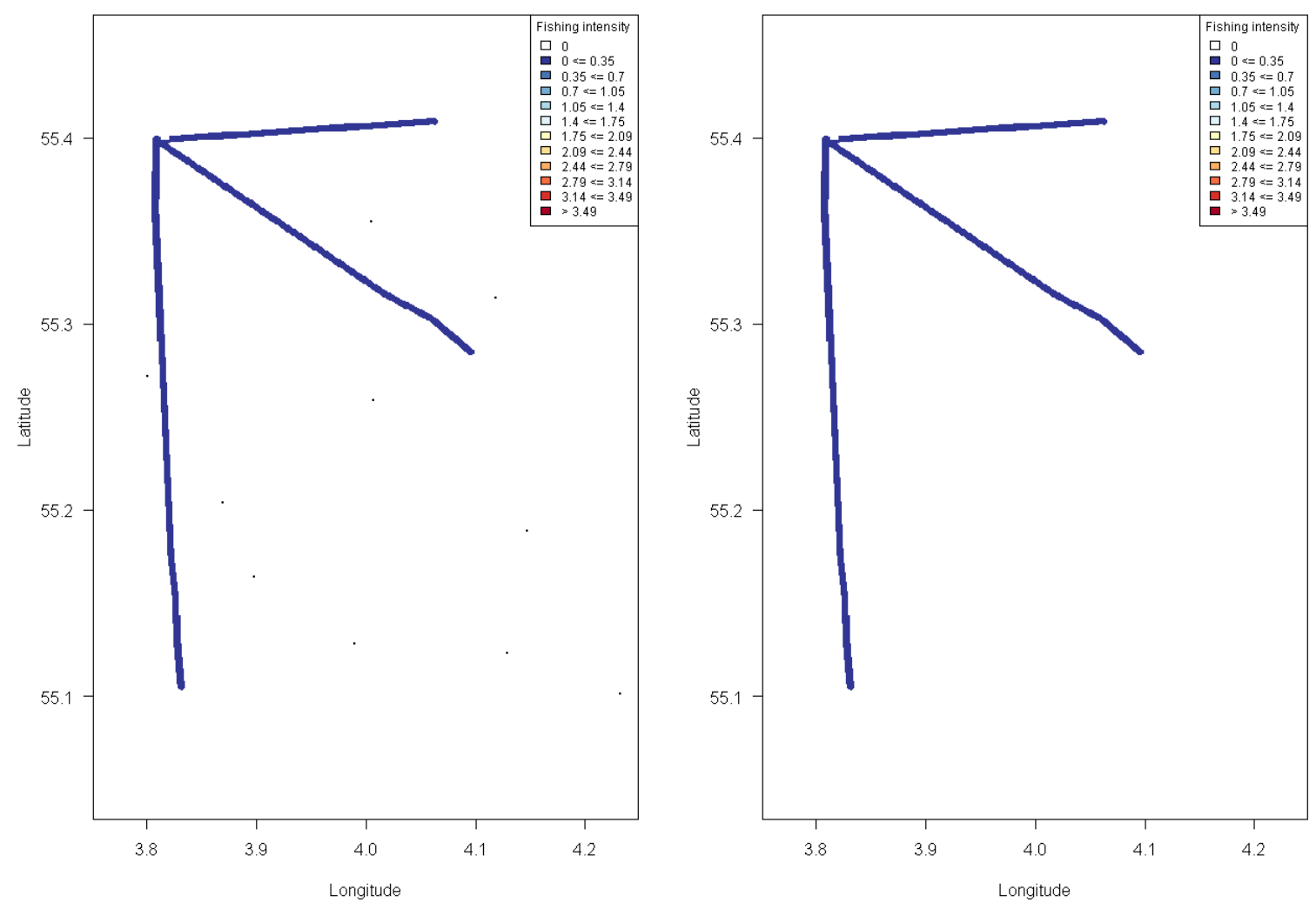

Figure 6. Fishing intensity of small bottom trawl vessels (excl shrimp trawlers) in the northern part of the Dutch EEZ. Left-hand figure includes $~ 10 \%$ of the VMS pings (black dots) that the analyses has been based on.
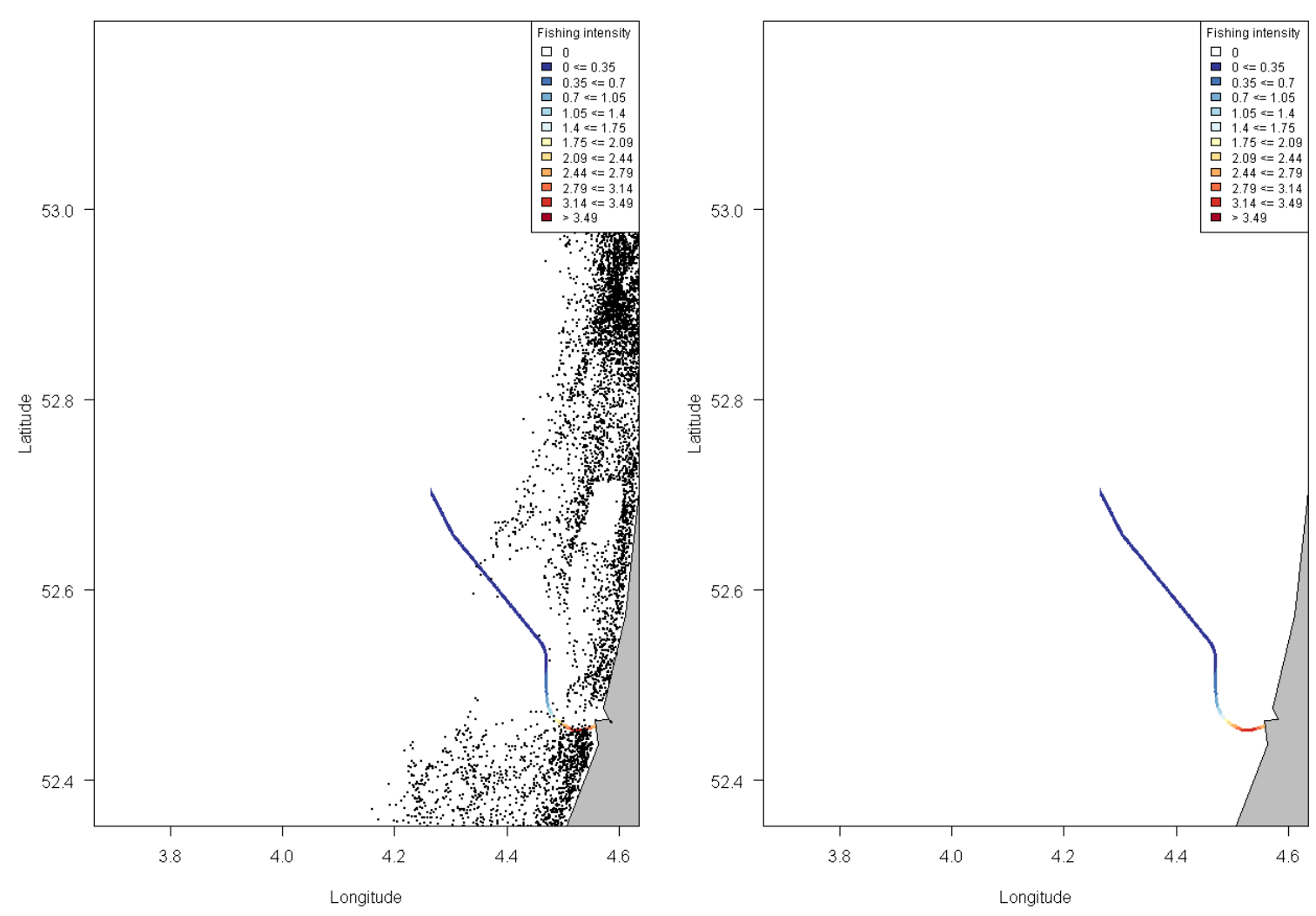

Figure 7. Fishing intensity of shrimp trawlers near the Dutch coastline. Left-hand figure includes $\sim 10 \%$ of the VMS pings (black dots) that the analyses has been based on.

Note that there is no fishing of shirmp vessels in the northern part of the Dutch EEZ. 
Results indicate that fishing near the Petrogas E\&P Netherlands B.V. pipelines is low to very low. Longterm average fishing intensity of the Dutch fleet indicate a similar pattern with low fishing intensity of larger and small vessels in near the Dutch coastline at the latitude of the IJmuiden harbour as well as low fishing intensity in the northern part of the Dutch EEZ. Highest fishing intensity is visible close to shore due to high abundance of shrimp trawlers. These trawlers are however associated to have lighter gear compared to small beam trawlers. Consequences of the weight of the gear to the risk of damaging pipelines is not assessed in the present study. 


\section{Conclusions and recommendations}

The results from this study show that the fishing activity in 2020 of the shrimp-trawl fleet are most relevant in the study area, and that fishing activity of other gears such as beam trawlers, flyshooters, otter trawlers and dredges is minimal. From a risk perspective, these gears may be less important than beam trawlers, otter trawlers or seines too, as they tow light gears over the seafloor.

No information is available on how much damage e.g. a small beam-trawl, a large beam-trawl or otter trawl gear would have on a pipeline although proxies for hydrodynamic drag have recently been derived. For this reason, all gears are treated similarly when expressing fishing effort indicators.

The indication of VMS pings in the figures, clearly show that no obvious avoidance strategy for pipelines is in place. The distribution of VMS pings in close vicinity of the pipelines is similar to areas further away from the pipelines. No direct 'attraction' of fishing activity to pipelines could be observed either, but clear indications of this would require further in-depth analyses. 


\section{Quality Assurance}

Wageningen Marine Research utilises an ISO 9001:2015 certified quality management system. This certificate is valid until 15 December 2021. The organisation has been certified since 27 February 2001. The certification was issued by DNV GL. 


\section{References}

Hintzen, N. T., Piet, G. J., and Brunel, T. 2010. Improved estimation of trawling tracks using cubic Hermite spline interpolation of position registration data. Fisheries Research, 101: 108-115. 


\section{Justification}

Report C055/21

Project Number: 43110000012-13

The scientific quality of this report has been peer reviewed by a colleague scientist and a member of the Management Team of Wageningen Marine Research

Approved: $\quad$ Drs. P. de Vries

Researcher

Signature:

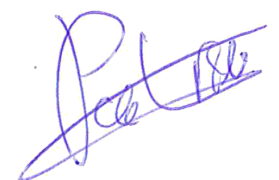

Date:

21 June 2021

Approved:

Drs. J. Asjes

Manager Integration

Signature:

Date:

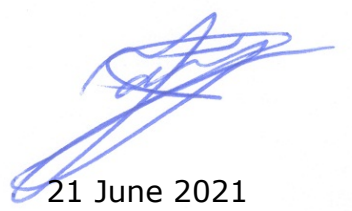


Wageningen Marine Research

T +31 (0)31748 7000

E: marine-research@wur.nl www.wur.eu/marine-research

Visitors' address

- Ankerpark 271781 AG Den Helder

- Korringaweg 7, 4401 NT Yerseke

- Haringkade 1, 1976 CP IJmuiden
With knowledge, independent scientific research and advice, Wageningen Marine Research substantially contributes to more sustainable and more careful management, use and protection of natural riches in marine, coastal and freshwater areas.

Wageningen Marine Research is part of Wageningen University \& Research. Wageningen University \& Research is the collaboration between Wageningen University and the Wageningen Research Foundation and its mission is: 'To explore the potential for improving the quality of life' 